Pediat. Res. 1: 354-363 (1967)

$\begin{array}{ll}\text { Respiratory } & \text { oxygenation } \\ \text { alkalosis } & \text { uterine blood flow } \\ \text { hyperventilation } & \text { hypocapnia } \\ \text { fetus } & \mathrm{pH}\end{array}$

\title{
Acute Maternal Respiratory Alkalosis (Hyperventilation) in the Pregnant Rhesus Monkey
}

\author{
R.E. Behrman ${ }^{[22]}$, J.T.PARER and M.J.Novy \\ Division of Perinatal Biology of the Department of Pediatrics, \\ and the Oregon Regional Primate Research Center, University of Oregon Medical School, \\ Portland, Oregon, USA
}

Extract

Maternal respiratory alkalosis from hyperventilation before delivery has been associated with depression and acidosis of some newborn infants. In these in utero studies of 6 primate fetuses, acute maternal hyperventilation significantly increased both the maternal and the fetal $\mathrm{pH}$ and thus increased the oxygen affinities of maternal and fetal hemoglobins. In comparison with the control period, during hyperventilation $71 \%$ more $\mathrm{CO}_{2}$ was removed from the uterus and its contents. The average $\mathrm{O}_{2}$ consumption by the uterus and placenta, $3.4 \mathrm{ml} / \mathrm{min}$, and the fetus, $2.1 \mathrm{ml} / \mathrm{min}$ was unchanged during hyperventilation. Mean $\mathrm{pO}_{2}$ in the umbilical vein during hyperventilation fell to $24.8 \mathrm{~mm} \mathrm{Hg}$ and saturation to $65 \%$, and umbilical blood flow increased from 40 to $45 \mathrm{ml} / \mathrm{min}$. Average uterine blood flow decreased slightly during hyperventilation. During these same comparison periods, neither maternal and fetal heart rate nor arterial venous pressures changed significantly. Thus, although $\mathrm{pO}_{2}$ and saturation in the umbilical and uterine venous blood decreased, the amount of oxygen delivered to each fetus remained relatively constant due in part to an increase in umbilical blood flow and to shifts in the oxygen dissociation curves of fetal and adult hemoglobins.

\section{Speculation}

A number of interrelated physiologic adjustments may take place on both sides of the placenta in response to maternal respiratory alkalosis in the primate without necessarily resulting in untoward effects on the fetus. However, any of a variety of additional clinical complications, particularly those that interfere with umbilical or uterine blood flow, might exceed the limits of intrauterine adjustment and compromise fetal oxygenation.

\section{Introduction}

Spontaneous maternal hyperventilation with room air or oxygen or the iatrogenic induction of hyperventilation during the administration of an anesthetic and oxygen for vaginal delivery or cesarean section are common events in obstetrical practice. Generally these maneuvers are not believed to be harmful to the fetus, but rather, on occasion, to improve fetal oxygenation.
The risk of fetal acidosis and hypoxia from maternal hypoventilation and respiratory acidosis are far greater and occur more frequently than the risks to the fetus from maternal respiratory alkalosis from hyperventilation [3, 6, 7]. Moya et al. [15] reported two infants who were depressed and acidotic at birth following labors complicated in part by severe maternal hyperventilation; they concluded that under certain circumstances extreme hyperventilation might be detrimental to the 
fetus and be a potential cause of neonatal morbidity and mortality. Recent studies in sheep have been cited as demonstrating that hyperventilation of the ewe with or without supplemental oxygen significantly reduced fetal $\mathrm{pO}_{2}$ and umbilical blood flow [14]. These data were interpreted by the authors to indicate that the oxygen supply of the sheep fetus was significantly reduced and prompted them to suggest that even moderate hyperventilation might be harmful in the human. However, these studies did not permit an adequate cvaluation of the acid-base status and the oxygenation of the fetus in utero because of the limited nature of the measurements performed and of the lack of a subsequent control period to evaluate the effects of a deteriorating fetus.

The present study was undertaken to determine if moderate short-term maternal hyperventilation, comparable to what might occur in clinical circumstances, resulted in untoward effects on the primate fetus. We have attempted to delineate the interrelated physiologic adjustments that take place on both sides of the placenta in response to mild maternal respiratory alkalosis in the primate. A variety of factors, such as changes in umbilical and uterine blood flows, differences in the $\mathrm{O}_{2}$ affinity of maternal and fetal bloods at various hydrogen ion concentrations, and the diffusion characteristics of the placenta for $\mathrm{O}_{2}, \mathrm{CO}_{2}$ and $\mathrm{HCO}_{3}^{-}$, play a role in the effects of maternal respiratory alkalosis on fetal oxygenation and acid-base balance.

\section{Materials and Methods}

Six pregnant Macaca mulatta monkeys were operated upon after being anesthetized with $\mathrm{N}_{2} \mathrm{O}$ and halothane. They were maintained on these gases while approximately $80 \%$ oxygen was administered with a Bird respirator through an endotracheal tube. Maternal body temperature was kept constant with circulating water heating pads. A Sanborn polyvisol recorder was used for continuous monitoring of maternal EKG, rectal temperature, respiratory rate and blood pressure. Temperature was determined with a thermistor probe calibrated with a mercury thermometer. Blood pressures were obtained with Statham pressure transducers.

Catheters were inserted into maternal carotid and femoral arteries, both utero-ovarian veins, the umbilical vein and the fetal femoral artery and vein as previously described $[4,17]$. The 'umbilical artery' blood samples were obtained through a catheter inserted proximally one and one-half inches in to the fetal femoral artery. Only one lower extremity of the fetus and a loop of umbilical cord were exposed for placement of the catheters and then returned to the uterus. The uterus was kept warm and moist throughout the entire proce- dure with minimal loss of amniotic fluid. The animals were maintained with a level of halothane anesthesia sufficient to eliminate significant uterine contractions without hypotension. Care was taken to avoid compression of the exposed uterine veins during the experiments.

Each animal was studied during an initial period, a period of hyperventilation, and a final control period. In each period, three consecutive sets of five simultaneously drawn blood samples were obtained from the catheters in the umbilical vein, fetal femoral artery, both maternal utero-ovarian veins and the maternal femoral artery. The first set of samples and the third set of samples in each period were used to determine the umbilical and uterine blood flows. The second set of samples was used for blood gas and acid-base analyses. Pressure measurements and fetal heart rates presented are those taken after the third set of blood samples were obtained in each period. Periods of artificial hyperventilation in these experiments ranged from $21 \mathrm{~min}$ utes to 70 minutes (table III).

Blood flows were measured by an application of the Fick principle adapted to the rhesus monkey $[4,13]$ and were calculated from the arteriovenous differences of tritiated water or antipyrine across the umbilical and uterine circulations. The plasma concentrations of antipyrine used in these experiments were measured with an accuracy of $\pm 2 \%$. These substances have been shown to be flow-limited with approximately equal placental clearances in this species [4]. A constant infusion into the fetal femoral vein with either of these substances resulted in a steady-state equilibrium after 50 minutes of infusion. The concentrations of antipyrine or tritiated water in the uterine vein and umbilical artery and vein were parallel and relatively steady after this period of time before the first control period samples were obtained. The concentration in the maternal artery was constant and negligible throughout the experiments. The total quantity of the infusate delivered to the fetus was determined by weight corrected for the specific gravity of the infusate and calculated from the exact moment of starting and stopping the constant speed pump and individual analysis of each infusate for antipyrine or tritiated water $[4,13]$. The uterine venous blood obtained was assumed to be representative of the venous drainage of the uterine circulation. A uterine blood flow was not calculated in those instances in which the concentration of antipyrine or tritiated water in the utero-ovarian vein was approximately equal to that in the artery since such veins probably do not drain a representative portion of the uterus and placenta $[11,17]$. When it was possible to calculate the uterine blood flow from both of the utero-ovarian veins, the results were averaged. 
Samples for blood gas analyses were collected anaerobically in heparin-fluoride treated syringes and placed in ice water. The $\mathrm{pH}$ was determined by a Radiometer water-jacketed glass electrode; $\mathrm{pO}_{2}$, by a Beckman macroelectrode, and $\mathrm{pCO}_{2}$ and bicarbonate were estimated by the Astrup system. All determinations were made at $38^{\circ}$ within 1 hour from collection. Fetal and maternal blood oxygen saturations were calculated from their respective oxygen dissociation curves $[5,16]$. The maximum error in this technique is estimated as approximately $\pm 5 \%$. Hemoglobin concentration was measured spectrophotometrically as cyanmethemoglobin and the $\mathrm{O}_{2}$ capacity of blood was calculated ( $1.34 \mathrm{cc} \mathrm{O}_{2}$ equivalent to $1 \mathrm{~g}$ hemoglobin). Total blood $\mathrm{CO}_{2}$ was calculated from the Van Slyke-Sendroy nomograms which have been validated for rhesus monkey blood [9]. The $p$ values presented were determined with Student's $t$-test of means.

\section{Results}

\section{A. Acid-Base Changes (table I)}

In each experiment, maternal hyperventilation resulted in significant hypocapnia $(\mathrm{p}<0.025)$ and alkalosis $(\mathrm{p}<0.01)$ compared to arterial samples obtained during control periods. There was also an associated decrease in the bicarbonate concentration. In every experiment but one, the fetal $\mathrm{pH}$ increased during the hyperventilation period compared to the values during the control periods $(p<0.01)$. This was true even in animal No. 6 in which the maternal pH reached 7.733 during hyperventilation.

In all animals except No. 1 , the $\mathrm{pCO}_{2}$ decreased on both the maternal and fetal sides of the placenta with hyperventilation. The decreases in uterine vein $\mathrm{pCO}_{2}$ and increases in uterine vein $\mathrm{pH}$ during hyperventilation were significant $(\mathrm{p}<0.025$ and $\mathrm{p}<0.05$, respectively). The maternal changes during hyperventilation were associated with wider arteriovenous $\mathrm{pH}$ and $\mathrm{pCO}_{2}$ differences in the umbilical circula tion when compared to the control arteriovenous differences $(p<0.025$ and $\mathrm{p}<0.05$, respectively), and there was a significant increase in the arteriovenous differences for total carbon dioxide for the uterus and its contents $(p<0.025)$. These changes are consistent with the removal of more carbon dioxide from the uterus and its contents during hyperventilation, assuming that the placenta simulates the characteristics of a concurrent flow placenta [4]. When the amount of carbon dioxide removed from the uterus and its contents was calculated from the product of the maternal venous-arterial difference for total $\mathrm{CO}_{2}$ and the uterine blood flow, it was found that an average of $71 \%$ more $\mathrm{CO}_{2}$ was removed from the uterus and its contents during hyperventilation than during the control periods.

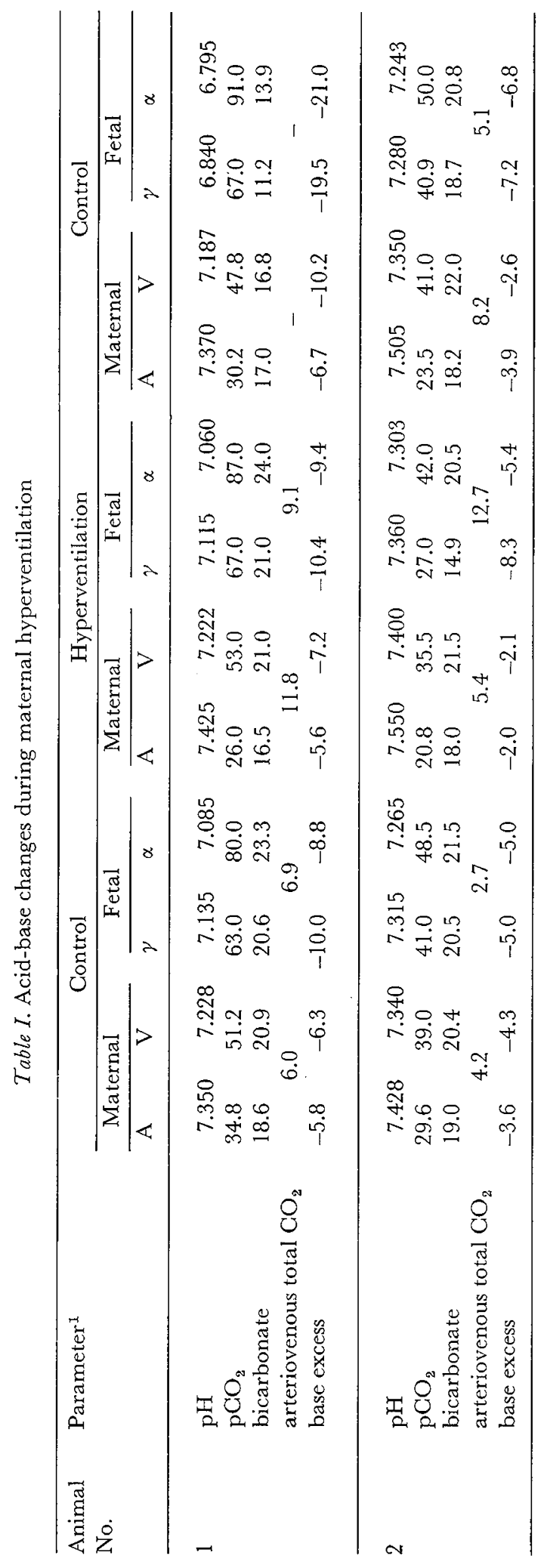


Acute maternal respiratory alkalosis (hyperventilation) in the pregnant rhesus monkey

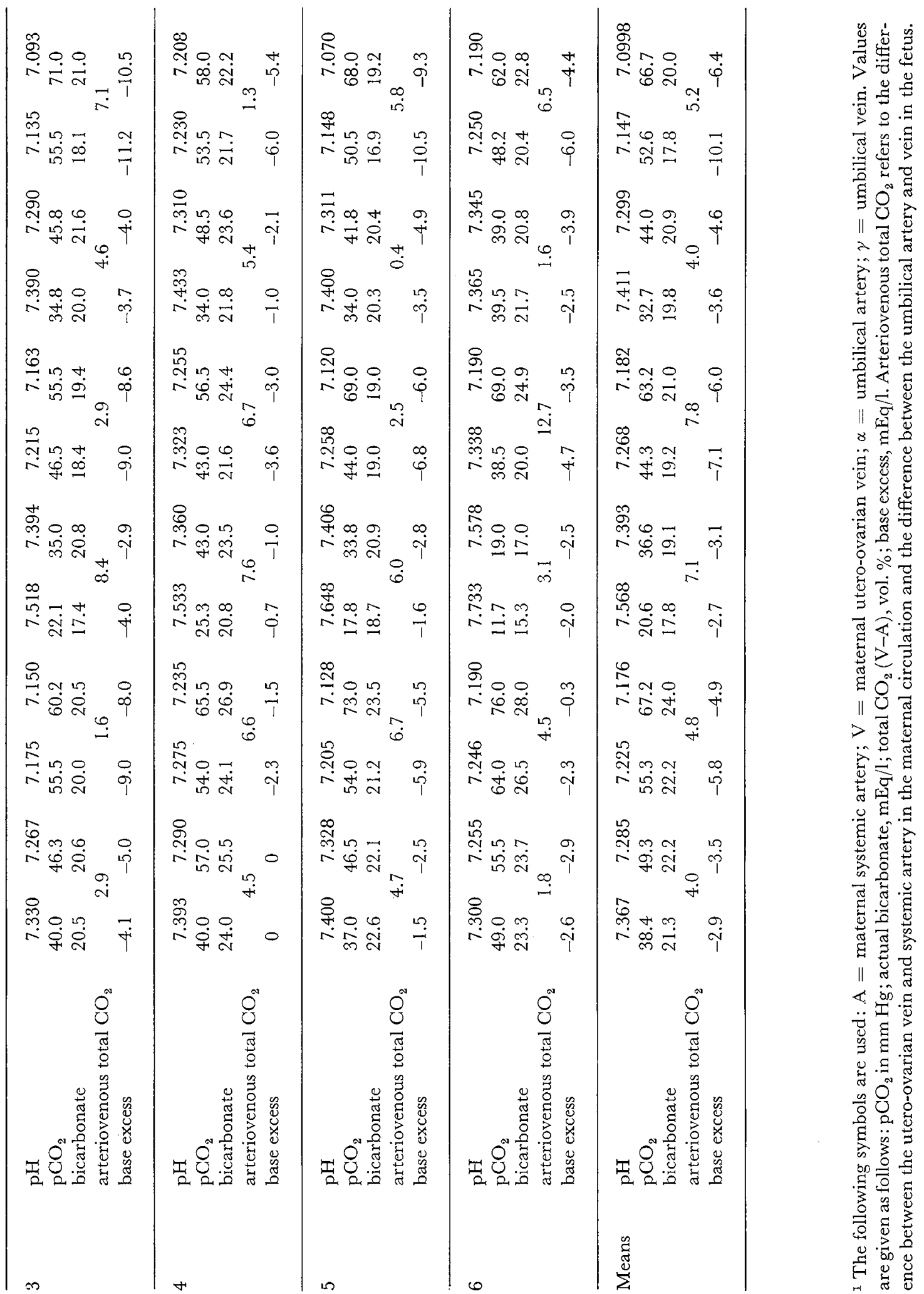


There was no significant change in maternal arterial base excess. The base deficit in the umbilical vein increased progressively during the experiment. This suggests that the increase was not related to the hyperventilation but rather to the duration of the experimental protocol.

\section{B. Oxygenation (table II)}

Neither the total amount of oxygen consumed by the uterus and its contents, average $3.4 \mathrm{ml} / \mathrm{min}$, nor by the fetus, average $2.1 \mathrm{ml} / \mathrm{min}$, changed significantly during the hyperventilation. The percentage of total oxygen delivered to the uterus that was extracted by the fetus did not change with hyperventilation; the average was $59 \%$.

Maternal hyperventilation with supplemental oxygen throughout the experiment resulted in stable high oxygen tensions and $100 \%$ saturation in the maternal arterial blood throughout each study. However, the uterine venous $\mathrm{pO}_{2}$ and saturation decreased with hyperventilation.

In each experiment, the fetal umbilical vein oxygen tension and saturation also decreased during maternal hyperventilation alkalosis. The mean umbilical vein $\mathrm{pO}_{2}$ fell to $24.8 \mathrm{~mm} \mathrm{Hg}$, and the average saturation decreased to $65 \%$. These values represent a $66 \%$ reduction in $\mathrm{pO}_{2}$ and a $79 \%$ reduction in saturation compared to the values in the first control period. Except for animal No.2, the fetal $\mathrm{pO}_{2}$ and saturation values rose again during the second control period. Thus the fetal umbilical vein $\mathrm{O}_{2}$ saturation fell during maternal hyperventilation despite a shift of the fetal blood oxygen dissociation curve to the left with the increase in the fetal $\mathrm{pH}$. Statistically significant parallel decreases in $\mathrm{pO}_{2}$ and $\mathrm{O}_{2}$ saturation, respectively, were observed during hyperventilation in the umbilical vein $(\mathrm{p}<0.05 ; \mathrm{p}<0.025)$ and the uterine vein $(\mathrm{p}<0.01$; $\mathrm{p}<0.005)$ compared to control periods. The maternal arteriovenous oxygen difference, however, was apparently adequate, and the uterine and umbilical blood flows were sufficient to maintain the same oxygen consumption during hyperventilation as during the control periods. In animal No.3, whose $\mathrm{pH}$ was 7.518 during hyperventilation, the amount of oxygen delivered to the fetus was not significantly reduced despite a moderate drop in both umbilical and uterine blood flows as well as in the fetal arterial and the venous $\mathrm{pO}_{2}$ and saturations.

\section{Hemodynamic Changes (tables III and IV)}

During hyperventilation, the mean umbilical blood flow was increased from $40 \mathrm{cc} / \mathrm{min}$ in the first control period to a value of $45 \mathrm{cc} / \mathrm{min}$. It decreased to $33 \mathrm{cc} /$ min in the second control period. This increase in umbilical blood flow is particularly significant as a gradual

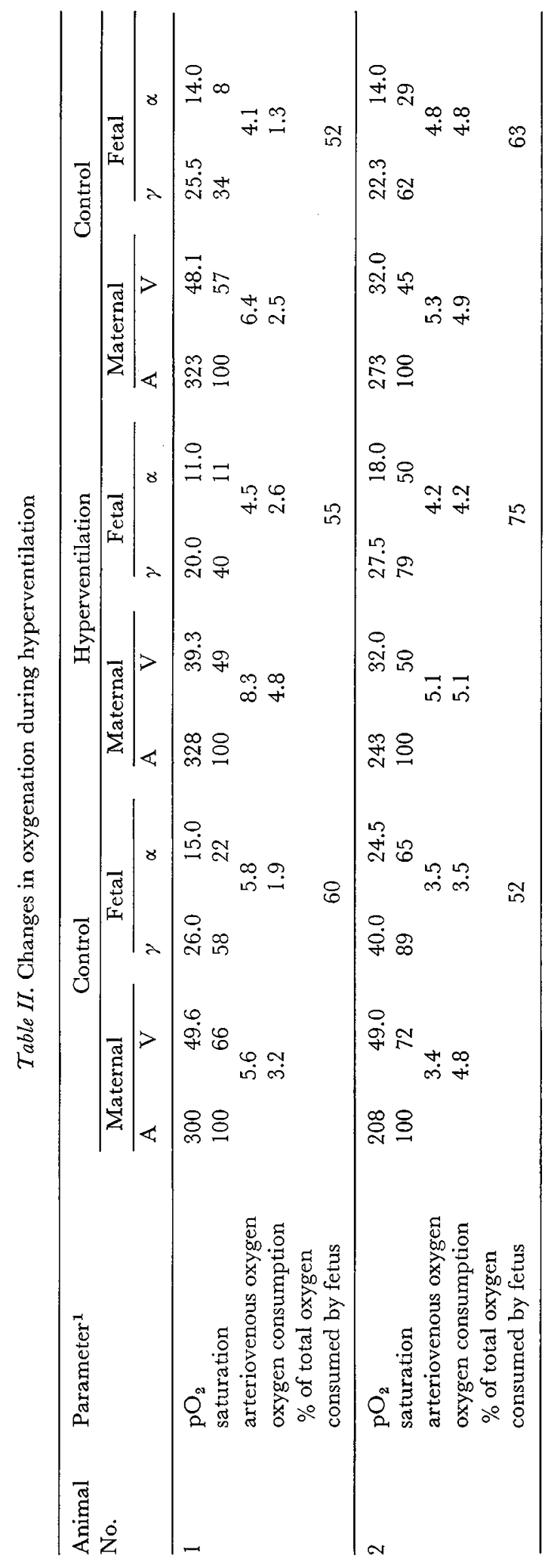


Acute maternal respiratory alkalosis (hyperventilation) in the pregnant rhesus monkey

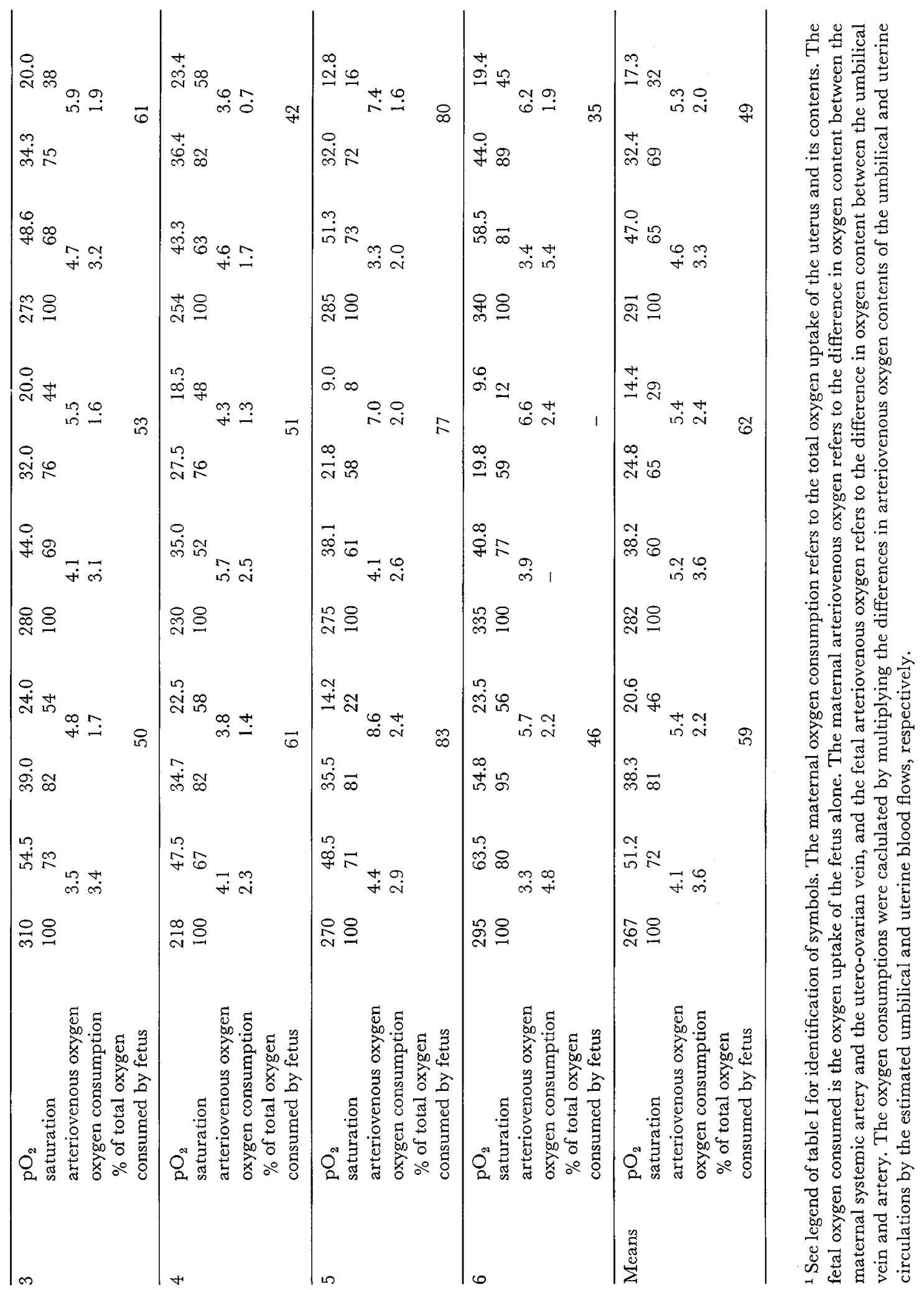


Table III. Effects of hyperventilation on uterine and umbilical blood flows

\begin{tabular}{|c|c|c|c|c|c|c|c|c|c|c|}
\hline \multirow{2}{*}{$\begin{array}{l}\text { Animal } \\
\text { No. }\end{array}$} & \multirow{2}{*}{$\begin{array}{l}\text { G.A. }{ }^{1} \\
\text { (days) }\end{array}$} & \multicolumn{2}{|c|}{ Weight (g) } & \multirow{2}{*}{$\begin{array}{l}\text { Duration of } \\
\text { hyper- } \\
\text { ventilation } \\
\text { (min) }\end{array}$} & \multicolumn{3}{|c|}{ Uterine blood flow ${ }^{2}$} & \multicolumn{3}{|c|}{ Umbilical blood flow } \\
\hline & & Fetus & Placenta & & $1 \mathrm{C}$ & $\mathrm{H}$ & $2 \mathrm{C}$ & $1 \mathrm{C}$ & $\mathrm{H}$ & $2 \mathrm{G}$ \\
\hline 1 & 152 & 467 & 128 & 70 & 57 & 57 & 46 & 33 & 57 & 32 \\
\hline 2 & 150 & 480 & 118 & 41 & 123 & 76 & 68 & 69 & 85 & 61 \\
\hline 3 & 146 & 366 & 98 & 31 & 97 & 75 & 71 & 35 & 30 & 33 \\
\hline 4 & 137 & 350 & 107 & 36 & 57 & 44 & 37 & 37 & 30 & 20 \\
\hline 5 & 160 & 434 & 118 & 21 & 71 & 62 & 55 & 27 & 29 & 21 \\
\hline 6 & 160 & 478 & 154 & 35 & 144 & - & 158 & 39 & 37 & 31 \\
\hline \multicolumn{5}{|c|}{ Averages } & 92 & 63 & 73 & 40 & 45 & 33 \\
\hline
\end{tabular}

${ }^{1}$ G.A. = gestational age

${ }^{2}$ Values are given in $\mathrm{cc} / \mathrm{min} .1 \mathrm{G}=$ first control period; $\mathrm{H}=$ hyperventilation period; $2 \mathrm{C}=$ second control period.

diminution in flow with time usually occurs in acute fetal surgical preparations. In three animals (Nos. 1, 2 and 5), there was an increase in the umbilical blood flow from the first control to the hyperventilation period with a subsequent decrease in the second control period. In one animal (No.3), there was a slight decrease in umbilical blood flow during the hyperventilation period with an increase during the subsequent control period. In animals No. 4 and 6 , there was a gradual decrease in umbilical blood flow throughout the course of the experiments. The umbilical blood flows during hyperventilation were significantly greater than during the second control periods ( $p<0.025)$.

The average uterine blood flow fell from $92 \mathrm{cc} / \mathrm{min}$ in the first control periods to $63 \mathrm{cc} / \mathrm{min}$ during hyperventilation and then rose to $73 \mathrm{cc} / \mathrm{min}$ in the second control periods. These averages include animal No. 6 in whom a uterine blood flow was not obtained during hyperventilation. When this animal is excluded, it is seen that both the means and individual uterine blood flows decreased progressively during each experiment. However, in each experiment, the percentage decrease in uterine blood flow was greater from the first control period to the hyperventilation period than from the hyperventilation period to the second control period. Thus, although the pattern of simultaneously estimated umbilical and uterine blood flows varied in the experiments, there was a tendency for umbilical blood flow to increase as uterine blood flow decreased during hyperventilation.

There were no significant changes in maternal or fetal heart rates and arterial venous pressures during the hyperventilation period in comparison with those of the control periods (table IV). There was a slight increase in vascular resistance in the uterine and umbilical circulations during the course of the experiment.
The average changes in maternal hematocrit and protein concentration during these experiments were $3 \%$ ( 0 to 7$)$ and $0.4 \mathrm{~g} \%$ (0.2 to 1.2$)$, respectively. The corresponding changes in the fetus were $8 \%(1$ to 10$)$ and $0.2 \mathrm{~g} \%$ (0.1 to 0.5$)$, respectively. These changes are consistent with the hemodilution that could be expected from the blood sampling and the flushing of indwelling catheters.

\section{Discussion}

The effects of hyperventilation were superimposed on a fetus that had become slightly acidotic as a consequence of the experimental manipulation of the uterus, placenta and fetus. In the initial control period, the fetuses tended to have a greater base deficit than their mothers. The fetal $\mathrm{pH}$ and bicarbonate values were lower and the base deficit greater in the second control period as compared to the first control period in all the experiments, although these differences were not statistically significant. The fact that the fetal heart rate, arterial and venous blood pressures and oxygen uptake were similar in the two control periods suggests that the degree of deterioration in the animal preparation did not obscure the effects of hyperventilation.

In these experiments, an increased amount of carbon dioxide was removed from the fetuses and they became more alkalotic in response to maternal respiratory alkalosis. There was no suggestion of an increased metabolic acidosis in mother or fetus due to hyperventilation per se $[8,19]$; lactate and pyruvate concentrations, however, were not measured [10].

It seems unlikely that the decreases in fetal oxygen tension and saturation due to maternal hyperventilation alkalosis were obscured by deterioration of the 
Acute maternal respiratory alkalosis (hyperventilation) in the pregnant rhesus monkey

Table IV. Changes in heart rate, blood pressure, rectal temperature and vascular resistance during hyperventilation

\begin{tabular}{|c|c|c|c|c|c|c|c|}
\hline \multirow{2}{*}{$\begin{array}{l}\text { Animal } \\
\text { No. }\end{array}$} & \multirow[t]{2}{*}{ Parameter $^{1}$} & \multicolumn{2}{|c|}{ Control } & \multicolumn{2}{|c|}{ Hyperventilation } & \multicolumn{2}{|c|}{ Control } \\
\hline & & Maternal & Fetal & Maternal & Fetal & Maternal & Fetal \\
\hline 1 & $\begin{array}{l}\text { heart rate } \\
\text { arterial pressure } \\
\text { venous pressure } \\
\text { vascular resistance } \\
\text { rectal temperature }\end{array}$ & $\begin{array}{l}180 \\
65 \\
2 \\
1.11 \\
38.5\end{array}$ & $\begin{array}{l}205 \\
25 \\
20 \\
0.15 \\
-\end{array}$ & $\begin{array}{l}157 \\
55 \\
4 \\
0.89 \\
37.9\end{array}$ & $\begin{array}{l}153 \\
35 \\
12 \\
0.40 \\
-\end{array}$ & $\begin{array}{c}174 \\
50 \\
4 \\
1.04 \\
37.9\end{array}$ & $\begin{array}{c}141 \\
35 \\
15 \\
0.63 \\
-\end{array}$ \\
\hline 2 & $\begin{array}{l}\text { heart rate } \\
\text { arterial pressure } \\
\text { venous pressure } \\
\text { vascular resistance } \\
\text { rectal temperature }\end{array}$ & $\begin{array}{c}185 \\
80 \\
5 \\
0.61 \\
38.3\end{array}$ & $\begin{array}{l}240 \\
30 \\
10 \\
0.29 \\
-\end{array}$ & $\begin{array}{c}192 \\
75 \\
7 \\
0.89 \\
38.5\end{array}$ & $\begin{array}{l}235 \\
25 \\
13 \\
0.14 \\
-\end{array}$ & $\begin{array}{c}192 \\
75 \\
7 \\
1.00 \\
38.7\end{array}$ & $\begin{array}{l}220 \\
24 \\
6 \\
0.30 \\
-\end{array}$ \\
\hline 3 & $\begin{array}{l}\text { heart rate } \\
\text { arterial pressure } \\
\text { venous pressure } \\
\text { vascular resistance } \\
\text { rectal temperature }\end{array}$ & $\begin{array}{c}180 \\
75 \\
14 \\
0.63 \\
37.5\end{array}$ & $\begin{array}{l}230 \\
45 \\
22 \\
0.66 \\
-\end{array}$ & $\begin{array}{l}160 \\
60 \\
12 \\
0.64 \\
37.5\end{array}$ & $\begin{array}{l}240 \\
38 \\
22 \\
0.53 \\
-\end{array}$ & $\begin{array}{l}160 \\
60 \\
15 \\
0.63 \\
38.0\end{array}$ & $\begin{array}{l}190 \\
40 \\
20 \\
0.61 \\
-\end{array}$ \\
\hline 4 & $\begin{array}{l}\text { heart rate } \\
\text { arterial pressure } \\
\text { venous pressure } \\
\text { vascular resistance } \\
\text { rectal temperature }\end{array}$ & $\begin{array}{c}170 \\
70 \\
9 \\
1.07 \\
37.3\end{array}$ & $\begin{array}{l}180 \\
29 \\
9 \\
0.54 \\
-\end{array}$ & $\begin{array}{l}174 \\
75 \\
11 \\
1.45 \\
37.4\end{array}$ & $\begin{array}{l}190 \\
22 \\
9 \\
0.43 \\
-\end{array}$ & $\begin{array}{c}190 \\
75 \\
5 \\
1.89 \\
37.5\end{array}$ & $\begin{array}{l}200 \\
21 \\
9 \\
0.60 \\
-\end{array}$ \\
\hline 5 & $\begin{array}{l}\text { heart rate } \\
\text { arterial pressure } \\
\text { venous pressure } \\
\text { vascular resistance } \\
\text { rectal temperature }\end{array}$ & $\begin{array}{c}165 \\
60 \\
3 \\
0.80 \\
38.0\end{array}$ & $\begin{array}{l}210 \\
31 \\
13 \\
0.66 \\
-\end{array}$ & $\begin{array}{c}140 \\
45 \\
3 \\
0.68 \\
37.6\end{array}$ & $\begin{array}{l}- \\
33 \\
6 \\
0.93 \\
-\end{array}$ & $\begin{array}{c}144 \\
65 \\
6 \\
1.07 \\
37.3\end{array}$ & $\begin{array}{l}200 \\
30 \\
12 \\
0.86 \\
-\end{array}$ \\
\hline 6 & $\begin{array}{l}\text { heart rate } \\
\text { arterial pressure } \\
\text { venous pressure } \\
\text { vascular resistance } \\
\text { rectal temperature }\end{array}$ & $\begin{array}{c}180 \\
90 \\
7 \\
0.58 \\
38.0\end{array}$ & $\begin{array}{l}200 \\
24 \\
4 \\
0.51 \\
-\end{array}$ & $\begin{array}{r}180 \\
60 \\
9 \\
- \\
37.9\end{array}$ & $\begin{array}{l}180 \\
36 \\
13 \\
0.70 \\
-\end{array}$ & $\begin{array}{c}180 \\
90 \\
6 \\
0.53 \\
38.1\end{array}$ & $\begin{array}{l}200 \\
33 \\
9 \\
0.77 \\
-\end{array}$ \\
\hline Means & $\begin{array}{l}\text { heart rate } \\
\text { arterial pressure } \\
\text { venous pressure } \\
\text { vascular resistance } \\
\text { rectal temperature }\end{array}$ & $\begin{array}{c}177 \\
73 \\
7 \\
0.80 \\
37.9\end{array}$ & $\begin{array}{l}211 \\
31 \\
13 \\
0.47 \\
-\end{array}$ & $\begin{array}{c}167 \\
62 \\
8 \\
0.91 \\
37.8\end{array}$ & $\begin{array}{l}200 \\
32 \\
13 \\
0.52 \\
-\end{array}$ & $\begin{array}{c}173 \\
69 \\
7 \\
1.03 \\
37.9\end{array}$ & $\begin{array}{c}192 \\
31 \\
12 \\
0.63 \\
-\end{array}$ \\
\hline
\end{tabular}

1 Values are expressed as follows: heart rate, counts/min; arterial pressure, $\mathrm{mm} \mathrm{Hg}$; venous pressure, $\mathrm{mm} \mathrm{Hg}$; vascular resistance, $\mathrm{mm} \mathrm{Hg} / \mathrm{cc} / \mathrm{min}$; rectal temperature, ${ }^{\circ} \mathrm{C}$.

24 Pediat. Res., Vol. 1, No. 5 (1967) 
fetus secondary to surgical manipulation since the $\mathrm{pO}_{2}$ tended to return to control levels after hyperventilation. However, no significant decrease in the amount of oxygen delivered to the uterus or in the oxygen uptake by the fetus could be detected by our methods. The hypotension, bradycardia, gasping and precipitous severe acidosis typical of anoxia did not occur [1, 2]. In all the experiments there was a moderate to marked increase in the maternal $\mathrm{pH}$ which, even with an unchanged uterine blood flow, could have resulted in a lowered uterine vein $\mathrm{pO}_{2}$ at about the same saturation, owing to a resultant increase in the oxygen affinity of maternal blood during the alkalosis. This increased maternal oxygen affinity would contribute to the fall in the umbilical $\mathrm{pO}_{2}$ observed, if the primate placenta simulates the characteristics of a concurrent flow placenta as has been suggested [4]. The increase in fetal $\mathrm{pH}$ resulting from the acute lowering of the fetal $\mathrm{pCO}_{2}$ increased the oxygen affinity of the fetal blood and resulted in a less marked fall in umbilical venous oxygen saturation than would have otherwise occurred at the lower initial fetal $\mathrm{pH}$. However, the decreases in fetal $\mathrm{pO}_{2}$ can only be partially accounted for by the shifts in the oxygen dissociation curves.

The uterine blood flows tended to decrease progressively during the course of the studies in each animal but it cannot be concluded that the fall was exclusively the result of the hyperventilation; in part it was probably due to deterioration of the animal preparation. This deterioration would also contribute to a decrease in uterine venous $\mathrm{pO}_{2}$. The uterine blood flows obtained in these studies compare well with those obtained by Meschia et al. and PARer et al. $[12,18]$ using the diffusion equilibrium technique on animals medicated with local procaine and 0.3 to $0.6 \mathrm{mg} / \mathrm{kg}$ of phencyclidine hydrochloride IM. They are also similar to uterine blood flows obtained in spontaneously ventilating primates studied with the technique used in this study under halothane anesthesia [11, 17]. The average umbilical blood flow during the hyperventilation period was greater than in either control period. Even if, as has been postulated [14, 15], a decrease in $\mathrm{pCO}_{2}$ resulted in uterine vasoconstriction and a decrease in uterine blood flow, the uptake of oxygen by the fetus was not significantly affected. Within the limits of our experiments, the decreased fetal $\mathrm{pO}_{2}$ that may have resulted from a slight decrease in uterine blood flow during acute 'moderate' hyperventilation, as well as the increased oxygen affinity of maternal blood, was sufficiently offset by increased umbilical blood flow and a shift in the fetal oxygen dissociation curve to maintain the same fetal oxygen consumption. Nor was the stress of maternal hyperventilation sufficient to cause significant alterations in fetal heart rate and in arterial and venous pressures. Although any effects of halothane anesthesia on the uterine and umbilical blood flows during these experiments would be superimposed on the effects of hyperventilation, the comparisons are valid for the limited purposes of this study since the anesthetic was kept constant throughout the control and test periods.

The interrelation of these different factors in maintaining fetal oxygenation can be illustrated by analysis of the experimental data of each animal individually. For example, in animal No. 5, despite a fall from an average fetal umbilical vein $\mathrm{pO}_{2}$ of $33.7 \mathrm{~mm}$ $\mathrm{Hg}$ during the control periods to $21.8 \mathrm{~mm} \mathrm{Hg}$ during hyperventilation with parallel decreases in uterine and umbilical vein saturations as the maternal $\mathrm{pH}$ went from 7.400 to 7.648 , there was no significant change in the fetal oxygen consumption. The fetal blood $\mathrm{pH}$ became more alkaline, thereby increasing the blood oxygen affinity, probably compensating in part for the increased maternal oxygen affinity resulting from her alkalosis. Although the uterine blood flow supplying oxygen decreased during hyperventilation, the umbilical blood flow increased slightly so that the total amount of $\mathrm{O}_{2}$ transported from mother to fetus per minute remained nearly the same.

In general, it appears that maternal respiratory alkalosis will result in fetal alkalosis and this will not necessarily be detrimental to the fetus. The overall effect on the fetus will depend on the resultant balance of a number of different physiologic adjustments. Clinically, a variety of factors may play a role in determining which fetuses are affected adversely by maternal respiratory alkalosis. Mild fetal acidosis secondary to labor or an alteration in maternal blood pressure due to anesthesia or drugs resulting in a decreased uterine blood flow might constitute enough of an additional insult to exceed the limits of intrauterine adjustment to the alkalosis and thereby compromise fetal oxygenation. The important observation by Moya et al. [15] that some infants born to mothers with serum $\mathrm{pH}$ as high as 7.65 had no clinical distress while two others born to mothers with severe hyperventilation had definite fetal distress with acidosis suggests that either the ability to adjust to this stress in utero was exceeded in the latter group and/or that some unknown additional stress occurred to compound any untoward effects of hyperventilation.

\section{Conclusions}

1. Moderate acute maternal hyperventilation resulting in an increase in maternal arterial $\mathrm{pH}$ to 7.733 and $\mathrm{a}$ reduction in $\mathrm{pCO}_{2}$ to $11.7 \mathrm{~mm} \mathrm{Hg}$ did not result in untoward effects on the primate fetus as measured by heart rate, blood pressure, venous and arterial pressures and changes in $\mathrm{pH}$. 
2. Maternal hyperventilation increased the fetal whole blood $\mathrm{pH}$ acutely and lowered the fetal blood $\mathrm{pCO}_{2}$. An increased amount of carbon dioxide was removed from the uterus and its contents.

3. The relation between the uterine and umbilical blood flows varied considerably from animal to animal. There appeared to be an increase in umbilical blood flow during hyperventilation in most but not all animals. The uterine blood flow decreased slightly but this change was not clearly associated with hyperventilation alone.

4. Although the umbilical venous and arterial $\mathrm{pO}_{2}$ and oxygen saturation values were significantly reduced in response to mild to moderate maternal respiratory alkalosis in these studies, the oxygen uptake of the fetus was not decreased.

\section{References and Notes}

1. Adamsons, K.; Behrman, R.E.; Dawes, G.S.; Dawkins, M.J.R.; James, L.S. and Ross, B.B.: The treatment of acidosis with alkali and glucose during asphyxia in foetal rhesus monkeys. J.Physiol. 169: 679 (1963).

2. Adamsons, K., Jr.; Bemrman, R.; Dawes, G.S.; JAmEs, L. S. and Koford, C. : Resuscitation by positive pressure ventilation and tris-hydroxymethylaminomethane of rhesus monkeys asphyxiated at birth. J.Pediat. 65: 807 (1964).

3. Battaglia, F. C.: The dangers of maternal hyperventilation. J. Pediat. 70: 313 (1967).

4. Battaglia, F. C.; Behrman, R.E.; Meschia, G.; Seeds, A.E. and Bruns, P.D.: Glearance of inert molecules, $\mathrm{Na}$ and $\mathrm{Cl}$ ions across the primate placenta. J. clin. Invest. (in press).

5. Behrman, R.E.; Heller, C.J.; Battaglia, F. G. and Hellegers, A. E.: A comparison of the oxygen affinity of maternal and fetal blood of the Macaca mulatta. Quart.J. exp. Physiol. 48: 258 (1963).

6. Blechner, J. N.; Meschia, G. and Barron, D.H. : A study of the acid-base balance of fetal sheep and goats. Quart.J. exp. Physiol. 45: 60 (1960).

7. Bruns, P.D.; Bowes, W.A., Jr.; Drose, V.E. and Battaglia, F. G.: Effect of respiratory acidosis on the rabbit fetus in utero. Amer.J. Obstet. Gynec. 87: 1074 (1963).

8. Eldridge, P. and Salzer, J.: Effect of respiratory alkalosis on blood lactate and pyruvate in humans. J.appl. Physiol. 22: 461 (1967).

9. Hellegers, A. E.; Heller, G.J.; Behrman, R. E. and Battaglia, F. C.: Oxygen and carbon dioxide transfer across the rhesus monkey placenta ( $M a c a-$ ca mulatta). Amer.J. Obstet. Gynec. 88: 22 (1964).

10. Huckabee, W.E.: Relationships of pyruvate and lactate during anaerobic metabolism. I. Effects of infusion of pyruvate or glucose and of hyperventilation. J. clin. Invest. 37: 244 (1958).

11. Meschia, G.; Behrman, R.E.; Bruns, P.D.; Seeds, A.E.; Lucey, J. and Battaglia, F.C.: Uterine and umbilical blood flow measurements in pregnant rhesus monkeys (in preparation).

12. Meschia, G.; Behrman, R. E.; Hellegers, A. E.; Schruefer, J.J.; Battaglia, F. G. and Barron, D.H.: Uterine blood flow in the pregnant rhesus monkey. Amer. J. Obstet. Gynec. 97: 1 (1967).

13. Meschia, G.; CotTer, J.R.; Makowskr, E.L. and BARRON, D.H.: Simultaneous measurement of uterine and umbilical flows and oxygen uptakes. Quart.J.exp. Physiol. 52: 1 (1967).

14. Motoyama, E.K.; Rivard, G.; Acheson, F. and Cook, G. D. : Adverse effect of maternal hyperventilation on the foetus. Lancet $i: 286$ (1966).

15. Moya, F.; Morishima, H. O.; Shnider, S. M. and JAMES, L.S.: Influence of maternal hyperventilation on the newborn infant. Amer.J. Obstet. Gynec. 91: 76 (1965).

16. PARER, J.T.: The $\mathrm{O}_{2}$ dissociation curve of blood of the rhesus monkey (Macaca mulatta). Resp. Physiol. 2: 168 (1967).

17. Parer, J.T. and Bemrman, R. E.: The oxygen consumption of the pregnant uterus and fetus of $M a-$ caca mulatta. Resp. Physiol. (in press).

18. Parer, J.T.; de Lannoy, G.W.; Hoversland, A.S. and MEtcalfe, J.: The effect of decreased uterine blood flow on uterine $\mathrm{O}_{2}$ consumption in pregnant macaques. Amer.J. Obstet. Gynec. (in press).

19. Plum, F. and Posner, J. B. : Blood and cerebrospinal fluid lactate during hyperventilation. Amer.J. Physiol. 212: 864 (1967).

20. Dr. Parer is presently in the Department of Obstetrics and Gynecology at the University of Washington School of Medicine, Seattle, Washington. Dr. Novy is a Research Associate of the National Institute of Child Health and Human Development.

21. Publication No.271 from the Oregon Regional Primate Research Center, supported in part by grant FR 00163 of the National Institutes of Health. This work was supported by grant No. HD 02757 from the National Institutes of Health.

22. Behrman, R.E., M.D., Oregon Regional Primate Research Center, 505 N.W. 185th Avenue, Beaverton, Ore. 97005 (USA). 